\title{
Seminário Grande sertão: veredas e Corpo de baile - 50 anos
}

\begin{abstract}
Em maio de 2006, foi realizado o Seminário Internacional Grande sertão: veredas e Corpo de baile - 50 anos. No texto a seguir, 0 principal organizador do evento, Prof. Heinz-Dieter Heidemann*, então Vice-Diretor do IEB, narra o evento e apresenta os textos das comunicações que se encontram publicados nesta edição:
\end{abstract}

Um seminário alembrável

Desde 1972, o Instituto de Estudos Brasileiros (IEB) abriga o Acervo João Guimarães Rosa, organizando, conservando e disponibilizando aos pesquisadores cerca de 20 mil documentos pessoais e os 3 mil exemplares da biblioteca particular do escritor. Em maio de 2006, o Instituto organizou o Seminário Internacional "Grande sertão: veredas e Corpo de Baile - 50 anos", em comemoração aos 50 anos da primeira publicação das duas obras. 0 evento reuniu, para um balanço crítico, grande número de reconhecidos estudiosos de Guimarães Rosa. O IEB fez jus, assim, mais uma vez, ao seu papel como um dos mais importantes centros interdisciplinares de pesquisa e documentação sobre cultura e história brasileiras.

Sob a condução da comissão organizadora, formada por Heinz Dieter Heidemann, Elizabeth Ziani, Lenira Marques Covizzi, Sandra Guardini T. Vasconcellos e Milton Ohata, durante cinco dias foram realizadas nove mesas-redondas: José Mindlin e "seu irmão mais moço” Antonio Candido abriram o seminário com depoimentos sobre seu convívio com Guimarães Rosa desde 1946, o ano da publicação de Sagarana. Foi Antonio Candido o primeiro a observar, em seus artigos pioneiros e seminais sobre o escritor, o amplo espectro de olhares possibilitado pela obra de Guimarães Rosa. Os debates reafirmaram essa perspectiva, abordando diversos aspectos interpretativos: lingüísticos, teórico-literários, históricos, geográficos, psicológicos, antropológicos, filosóficos.

Heloisa Starling (UFMG) - A república e o sertão - imaginação literária e republicanismo no Brasil, Willi Bolle (USP) - O

* professor do Departamento de Geografia da FFLCH da Universidade de São Paulo. 
Brasil jagunço - retórica e poética e Luis Roncari (USP) - 0 cão do sertão no arraial do Ão iniciaram as discussões analisando aspectos da formação nacional. 0 tema da violência, vivida intensamente em São Paulo no dia da apresentação - em pleno ataque do PCC à metrópole -, orientou boa parte dos comentários e das discussões da mesa "O país de Rosa".

Edna Maria Nascimento (UNESP/UNIFRAN) - Metalinguagem em Grande sertão: veredas, Nilce Sant'Anna Martins (USP) - Simplicidade e beleza na linguagem de "Campo Geral" - e Cecília de Lara (USP) - João Guimarães Rosa: ourives da palavra compuseram a mesa "Língua linguagens".

Carlos Rodrigues Brandão (UNICAMP) - O sertão errante e Sandra Guardini T. Vasconcellos - Caminhos do sertão: impasses da modernidade relataram os seus trabalhos de campo e estudos sobre os "Sertanejos sábios sabidos".

Heloisa Vilhena de Araújo (Secretaria de Estado das Relações Exteriores, Brasília) - O tema da idade de ouro em Grande Sertão: Veredas, Héctor Olea (Museum of Fine Arts, Houston, EUA) - O construi de desconfiar: a estrutura modular intertextual e Suzy Frankl Sperber (UNICAMP) - Filosofia platônica e ficção rosiana: transposições debruçaram-se sobre o tema "Outros textos no texto", examinando os fundamentos filosóficos relevantes na criação do autor.

Benedito Nunes (UFPA) - Guimarães Rosa quase de cor, Francis Utéza (Universidade Paul Valéry de Montpellier, França) - Grande sertão: veredas - o recado do pentagrama e João Adolfo Hansen (USP) - Forma e indeterminação em Grande sertão: veredas analisaram o "Sertão mundo" a partir de seus contatos pessoais com Guimarães Rosa, de estudos filosóficos, de valores metafísicos e religiosos e, sempre, da teoria literária.

Ettore Finazzi-Agrò (Universidade Roma "La Sapienza", Itália) - Pós-tudo - banimento e abandono no Grande sertão e Susana Kampff Lages (UFF) - Depois de Babel: Guimarães Rosa e a violência da tradução abordaram as polaridades e os momentos decisivos das relações entre espaço e história, entre autor e tradutor.

Adélia Bezerra de Menezes (UNICAMP USP) - $O$ pathos amoroso em “Dãolalalão”, Cleusa Rios Pinheiro Passos (USP) - Grande sertão: veredas - no redemunho das cantigas e Márcia Marques de Morais (PUC/MG) - Coração mistura amores: o desejo deslocado nas veredas do Grande Sertão contribuíram com olhares psicanalíticos em busca de um entendimento dos "Avessos do Homem”.

Maria Aparecida Santilli (USP) - João Guimarães Rosa e José Luandino Vieira: a voz e a letra, Ana Luiza Martins Costa (Fundação Casa de Rui Barbosa) - O mundo escutado e Marli 
Fantini (UFMG) - Por que ler Grande sertão: veredas no seu 50 aniversário? apresentaram suas reflexões sobre os "Confrontos".

Kathrin Holzermayr Rosenfield (UFRGS) - Grande sertão: veredas entre os românticos alemães e os ensaístas brasileiros, Walnice Nogueira Galvão (USP) - Parolagem na venda e Eduardo F. Coutinho (UFRJ) - Discursos, fronteiras e limites na obra de Guimarães Rosa fecharam o seminário na última mesa-redonda, “Grande sertão: veredas e Corpo de Baile - 50 anos".

Como comentaristas e/ou coordenadores das mesas, Heinz Dieter Heidemann (USP), Maria Cecília de Moraes Leonel (UNESP), Flávio Aguiar (USP), Lélia Parreira Duarte (PUC/ MG), Cecília de Lara (USP), José Antonio Pasta Jr. (USP), Tales Ab'Saber (Instituto Sedes Sapientiae/SP), Lenira Marques Covizzi (UNESP) e Milton Ohata (IEB-USP) contribuíram com problematizações e questionamentos em todos os debates.

$\mathrm{O}$ evento incluiu também dois mini-cursos: Carlos $\mathrm{Au}-$ gusto de Figueiredo Monteiro, Professor Emérito de Geografia da USP, ministrou o curso Mensagens geográficas n"'0 recado do morro", e a Professora Neuma Barreto Cavalcante, que pertenceu ao IEB-USP até 2005, lecionando atualmente na UFCE, coordenou o curso $O$ processo de criação literária e o arquivo do IEB.

0 seminário contou ainda com três exposições: Rastros em escritura, com a curadoria de Mônica Gama e Vitor Borysow, que apresentou documentos do arquivo do IEB; Saudades de Rosa, mostra de fotografias de Germano da Silva; e Bordados e artesanato sertanejo, com trabalhos do grupo "Teia de Aranha" (SP) e de bordadeiras do sertão de Cordisburgo, Morro da Garça e Andrequicé.

0 êxito do seminário deveu muito aos encantadores contadores de histórias dos grupos "Miguilim”, formado por adolescentes de Cordisburgo, terra natal de Guimarães Rosa, e “Tudo era uma vez", de Belo Horizonte. Os contadores introduziram a abertura e todas as mesas redondas do evento, narrando trechos selecionados de Corpo de baile e Grande sertão: veredas.

Para dar apenas uma pequena amostra da diversidade e profundidade das discussões, publicamos na íntegra, nesta edição da Revista do Instituto de Estudos Brasileiros, os textos de três das palestras realizadas durante o seminário:

O Brasil jagunço - retórica e poética, de Willi Bolle, Professor Titular da Faculdade de Filosofia, Letras e Ciências Humanas da USP e pesquisador da obra de Guimarães Rosa desde sua tese de doutorado, defendida na Alemanha: (Fórmula e fábula, 1973). Publicou vários artigos e livros, o mais recente deles grandesertão.br (2004).

Partindo de reflexões de Euclides da Cunha, Oliveira Vianna, Raymundo Faoro e Caio Prado Júnior sobre banditismos, 
“desenraizados" e a relação entre poder, crime e justiça no Brasil, Bolle desenvolve sua interpretação da obra de João Guimarães Rosa para ler melhor e de forma mais profunda, através do "sistema jagunço", os "retratos sociológicos e historiográficos do Brasil".

Em seu artigo, Bolle demonstra como o escritor dialoga profundamente com os retratos do Brasil e expõe a maneira como crime e lei se completam na formação nacional, baseada no poder patrimonial (o coronelismo) e no poder estamental, da corporação dos altos funcionários do estado.

Entre mitificação e desmitificação, o jagunço é um rebelde que ratifica seu "sistema" e busca legitimar sua guerra contra o governo repressor. Na jagunçagem, o chefe pode "condenar de absolvido”. Em Grande sertão: veredas, a análise radical de si mesmo leva Riobaldo a entender o sertão como arqui-paisagem da violência, na forma de um retrato da sociedade brasileira como um todo. A obra de Guimarães Rosa transmite assim imagens essenciais da estrutura política e social vigente.

Pós-tudo. Banimento e abandono no Grande Sertão, de Ettore Finazzi-Agrò, Professor Catedrático (Titular) de Literaturas Portuguesa e Brasileira na Faculdade de Ciências Humanas da Universidade de Roma "La Sapienza”. Publicou, entre outros, o livro Um lugar do tamanho do mundo. Tempos e espaços da ficção em João Guimarães Rosa (2001).

0 texto de Ettore foi considerado pelo comentador José Antonio Pasta Jr. “delicado, de uma dialética sutil”. A partir de reflexões sobre a natureza póstuma da cultura e do pensamento contemporâneos, o autor enfatiza o caráter histórico da criação e interpretação literárias, em particular da "travessia inconclusa” na obra rosiana. Nas "dobras da estória” e vagueando entre os tempos da narrativa, aponta para a barbárie, o tumulto e a violência, mas também para a chance de escapar deles. Os catrumanos, banidos e abandonados do espaço geográfico e do tempo histórico, servem como objeto específico da análise. Profundo conhecedor da bibliografia dedicada à obra rosiana, Ettore Finazzi-Agrò desenvolve suas reflexões sobre as articulações entre violência e arbitrariedade, território e história, banimento e abandono.

0 tema da idade de ouro em Grande sertão: veredas, de Heloisa Vilhena, Ministra de Primeira Classe da Carreira de Diplomata. Publicou vários livros sobre a obra de Guimarães Rosa, entre eles Guimarães Rosa: diplomata (1987); A raiz da alma (1992) e $O$ roteiro de deus (1996):

Vilhena tece considerações sobre a temática da Idade de Ouro desde Hesíodo, Aratus e Virgílio: a primavera eterna do mundo puro e harmônico. Tendo como pano de fundo a crítica 
da razão iluminista kantiana, baseada no tempo e no espaço racional, a autora examina as obras de Dante, Cervantes e Lewis Carroll (na qual o relógio pode voltar atrás) e reconhece em Riobaldo, que quer acabar com o mal na terra, a nostalgia de uma Idade de Ouro. A volta ao paraíso terrestre se dá através da obra de arte e da linguagem, representação do todo. Há coisas invisíveis atrás dos nomes e das palavras, atrás de Diadorim há Deus, a utopia e o ideal da Idade de Ouro.

Esperamos que os três textos publicados estimulem o interesse pela leitura do livro contendo todas as palestras, que ainda está no prelo. Desde já, o relatório final ilustrado e os DVDs com todas as mesas redondas - incluindo as apresentações dos contadores de estórias - estão à disposição dos pesquisadores no arquivo do IEB. 